\title{
PTU-049 CHARACTERISTICS OF COELIAC DISEASE (CD) IN A COHORT OF ELDERLY PATIENTS
}

doi:10.1136/gut.2011.239301.177

S Casella, ${ }^{1}$ B Zanini, ${ }^{*}$ F Lanzarotto, ${ }^{1}$ V Villanacci, ${ }^{2}$ A Magni, ${ }^{1}$ F Caselani, A Lanzini ${ }^{1}{ }^{1}$ Medicine-Gastroenterology Unit, University of Brescia, Brescia, Italy; ${ }^{2}$ Histopathology, University of Brescia, Brescia, Italy

Introduction $\mathrm{CD}$ is increasingly being diagnosed in elderly patients, but little information is available on clinical characteristics and on response to gluten free diet (GFD) in elderly CD.

Methods To characterise CD in patients aged $\geq 65$ years by comparison with patients aged 18-65 years and to assess the effects of GFD. Information on clinical, serological and histological characteristics collected before and during GFD were retrieved retrospectively from $\mathrm{CD}$ database of patients attending our Clinic from 1991 to 2010. We identified two cohorts of patients: Group A, age $\geq 65$ years ( $n=59$ patients); Group B, age range $18-64$ years $(n=1166)$.

Results Elderly patients represented $5 \%$ of patients in our database. Mean \pm SEM age was $70 \pm 0.6$ years (range $65-83$ ) in 
Table 1 PTU-049 Neuropsychological tests in CD patients (Group A) and in Control subjects (Group B)

\begin{tabular}{lcccccc}
\hline & Before GFD & \multicolumn{7}{c}{ During GFD } \\
\hline & Group A & Group B & p & Group A & Group B & p \\
\hline Haemoglobin (mg/dl) & $12.12 \pm 0.3$ & $12.73 \pm 0.1$ & 0.02 & $13.12 \pm 0.31$ & $13.3 \pm 0.05$ & 0.5 \\
Albumin (g/dl) & $57.59 \pm 0.92$ & $61.19 \pm 0.15$ & $<0.0001$ & $58.47 \pm 1.17$ & $62.26 \pm 0.15$ & $<0.0001$ \\
Calcium (mg/dl) & $8.72 \pm 0.2$ & $9.1 \pm 0.03$ & 0.0043 & $9.1 \pm 0.17$ & $9.28 \pm 0.02$ & 0.06 \\
Vitamin D (ng/ml) & $15.48 \pm 2.02$ & $20.9 \pm 0.45$ & 0.01 & $21.88 \pm 3.43$ & $23.3 \pm 0.77$ & 0.7 \\
Vitamin B12 (pg/ml) & $463.9 \pm 86$ & $348.6 \pm 6.3$ & 0.0007 & $373.3 \pm 29.3$ & $385.1 \pm 6.84$ & 0.7 \\
Parathyroid hormone (pg/ml) & $91.45 \pm 16.7$ & $67.2 \pm 2.5$ & 0.05 & $60.71 \pm 6.37$ & $50.5 \pm 1.16$ & 0.1 \\
Bone ALP (U/l) & $89.19 \pm 16.66$ & $42.69 \pm 2.2$ & $<0.0001$ & $43.25 \pm 5.62$ & $28.8 \pm 0.77$ & 0.004 \\
T-score lumbosacral & $-3.01 \pm 0.37$ & $-1.01 \pm 0.07$ & $<0.0001$ & $-2.62 \pm 0.79$ & $-0.82 \pm 0.08$ & 0.0006 \\
Marsh III & $81 \%$ & $93 \%$ & 0.2 & $21 \%$ & $19 \%$ & 0.5 \\
\hline
\end{tabular}

group A and $35.2 \pm 0.3$ (range 18-64) in group B; male/female ratio was $1 / 2.7$ in both Groups. body mass index (BMI) was $22.5 \pm 0.7$ in group $A$ and $21.6 \pm 0.1$ in group $B$ respectively $(p=0.1)$. Prevalence of diarrhoea ( $49 \%$ vs $41 \%, p=0.3)$ and abdominal pain $(27 \%$ vs $31 \%$, p=0.6) was similar, but weight loss ( $37 \%$ vs $21 \% \mathrm{p}=0.005)$ and dyspepsia $(22 \%$ vs $12 \%$; $=0.04)$ were more frequent in group $\mathrm{A}$ than $\mathrm{B}$. Incidence at diagnosis of non-Hodgkin lymphoma (NHL) was higher in group A ( $5 \%$ ) than group $\mathrm{B}(0.3 \%, \mathrm{p}=0.003)$. Differences before and during GFD on selected parameters are summarised in table 1.

Conclusion CD is a common disease in the elderly and can be diagnosed in patients as old as 83 years of age. Clinical presentation is similar in the elderly as in younger patients, but elderly patients present more frequently with weight loss and bone disease. NHL is already present at time of CD diagnosis in a substantial proportion of elderly patients, emphasizing the importance of early diagnosis. Histological improvement during GFD is similar in elderly as in younger patients, but improvement of laboratory parameters is less marked in elderly CD.

Competing interests None.

Keywords coeliac disease, elderly. 